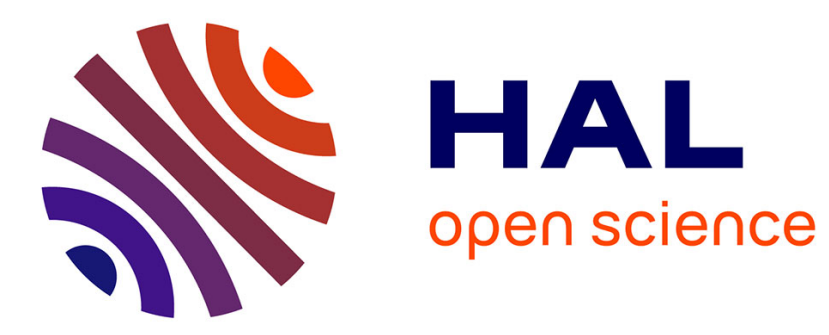

\title{
Modal shift potential of improvements in cycle access to exurban train stations
}

\author{
Sophie Midenet, Etienne Come, Francis Papon
}

\section{To cite this version:}

Sophie Midenet, Etienne Come, Francis Papon. Modal shift potential of improvements in cycle access to exurban train stations. Case Studies on Transport Policy, 2018, 34p. 10.1016/j.cstp.2018.09.004 . hal-01882603

\section{HAL Id: hal-01882603 https://hal.science/hal-01882603}

Submitted on 27 Sep 2018

HAL is a multi-disciplinary open access archive for the deposit and dissemination of scientific research documents, whether they are published or not. The documents may come from teaching and research institutions in France or abroad, or from public or private research centers.
L'archive ouverte pluridisciplinaire HAL, est destinée au dépôt et à la diffusion de documents scientifiques de niveau recherche, publiés ou non, émanant des établissements d'enseignement et de recherche français ou étrangers, des laboratoires publics ou privés. 
Midenet Sophie, Côme Etienne, Papon Francis, Modal shift potential of improvements in cycle access to exurban train stations, Case Studies on Transport Policy, 2018 (on line). DOI: 10.1016/j.cstp.2018.09.004 


\title{
Modal shift potential of improvements in cycle access to exurban train stations
}

\begin{abstract}
This paper addresses the question of bicycles as an access mode to train stations in exurban areas. The aim is to provide a method to estimate the modal shift potential from car to cycle (regular bike or pedelec) for residents accessing the station. Putting a figure on this potential makes it possible to refine policies for promoting cycle access to stations like sizing the cycle parking infrastructure, and to assess the benefits of bike and ride solutions for users and communities. Focusing on exurban areas where the level of cycling is low, the study describes a prospective approach to assess the modal shift potential from car to cycle under the assumption of favoring cycle access conditions resulting from proactive policies. In order to build scenarios at a suitable scale for cycling mobility, several high resolution datasets and mapping tools are integrated to support access mode share modeling within the catchment area of the station. The paper describes the access mode share model and its use for prospective analysis about shift potential from car to cycle, on the basis of contrasting scenarios for cycle access conditions and for changes in station ridership. The various modal shift hypotheses are discussed. The method is applied to Val d'Amboise, a French exurban territory with good quality train services and room for growth for cycle access to the station. The prospective situation under a bicycle-friendly scenario is characterized by similar modal shares for the car and the bicycle as access modes to the station, including a high level of pedelec use. Car parking access control at the station would be a key factor to achieve such a modal shift.
\end{abstract}

Keywords. Bicycle and train integration, modal shift to cycling, exurban areas, potential estimation, prospective 


\section{Introduction}

Integrating bicycles and transit can provide time-efficient, environment-friendly and cost-saving trip chains that may reduce car dependency (Kager et al., 2016), especially in exurban areas. In those areas, the sprawling of population makes walking to the station impractical for most residents, and public transport is often infrequent and inadequate to service dispersed settlements. The promising growth in the use of pedelecs (bicycles with electric assistance limited to $250 \mathrm{~W}$ and $25 \mathrm{~km} / \mathrm{h}$ ) could lead to even greater time competitiveness, where bicycles and regional trains are integrated in such areas. Bicycle and train integration potential mainly concerns access to the station, as opposed to egress (Hegger, 2007; Martens 2007), since travelers keep their bikes at home rather than at work. In the Netherlands, for instance, bicycles are the first access mode and only the third egress mode after walking and urban public transportation (Givoni and Rietveld, 2007).

Our aim is to provide a method to estimate the modal shift potential from car to bicycle for residents accessing a train station in exurban areas. Putting a figure on this potential facilitates the adoption of local measures favoring cycle access, like sizing the cycle parking infrastructure in the vicinity of the station. It also makes it possible to assess the economic benefit for the local community that proactive policies favoring "bike and ride" $(\mathrm{B}+\mathrm{R})$ could provide.

In areas where cycling is not so highly developed, as in many French exurban areas, if the local authorities want to encourage train users to shift from car to cycle to access the station, it is first of all necessary to set up favorable cycling conditions, with bicycle parking facilities and good quality cycle routes between the residential areas and the station. This needs time and ambitious policies, which is why a prospective approach is proposed to estimate the modal shift potential under the assumption of 
favoring cycle access to the station. The aim of this paper is to provide an estimate of this potential cycle modal share as an access mode to the station, given the technical characteristics (mostly travel time) of cycles and cars. In order to build scenarios at a suitable scale for cycling mobility, high resolution datasets and mapping tools are used and integrated to support access mode share modeling within the catchment area of the station. The aim of the paper is to describe this access mode share model and its use for prospective analysis about shift potential from car to cycle.

The analysis is applied to a French exurban territory in the Centre-Val de Loire region, the Val d'Amboise. Amboise is a town (13,000 inhabitants, twice as many if the urban area is taken into account), located in the vicinity of the city of Tours $(350,000$ inhabitants). Amboise is connected to Tours by regional train: $22 \mathrm{~km}$ length service in about 20 minutes travel time, 23 departures per working day in each direction. If journeys from city center to city center are considered, the train is competitive compared to the car since the time needed to go by car from door to door in peak hour is over 30 minutes. The train market share in total trip market reaches $10.4 \%$ for Amboise residents who commute to Tours or elsewhere (see Papon et al., 2017, for details of the reconstitution of the present commuting market and modal share in Amboise area). Bicycle use for transportation in Amboise is presently low in spite of small distances within the city and a flat Loire valley area (but surrounded by hills). Today, the main access modes used by Amboise residents to reach the station are car (66\%) with or without car parking ("park and ride" or car drop-off) and walking (23\%). Urban shuttles (a single line serving Amboise station with irregular schedules), county coaches, taxis or motorized two wheelers are not much used in this exurban area, with together a modal share below 4\%. Bicycle share reaches 7\%, half being boarded bikes and half being parked bikes. Despite hills on both sides of the Loire Valley, pedelecs are not 
used presently as a station access mode, probably due to the lack of secured bike parking spaces.

The Amboise area is an attractive case study as it is a medium-sized exurban territory, with good quality train services and unexploited potential for growth for cycle access to the station. Our method for assessing the potential modal shift from car to cycle access is illustrated with this case but can be applied to other areas with similar features and comparable modal share for station access (mostly car, low bicycle use, low public transport use, hardly any pedelec).

The paper first describes the framework for addressing station access mode in a prospective approach based on evolution scenarios. Section 3 presents the principles of the spatial model we have developed to infer access mode share potential within the catchment area and describes the hypothesis derived from the bicycle-friendly scenario to fix modal shift intensity (magnitude of shift rates). The Amboise case study and the resulting prospective situation are described in the last section before conclusive discussion. 


\section{Framework}

\subsection{Prospective scenarios on cycling policies}

It is assumed that the potential for cycle access would be realized under optimal cycling feeder conditions ${ }^{1}$. For an area to become bicycle-friendly, clearly proactive policies are required in order to adapt public space and to contain motorized travel. The impact of specific proactive policy measures on a given territory cannot be drawn precisely. However, local action plans to favor bicycle and train integration are quite well-known: good feeder routes for bicycles (Mueller and Hunter-Zaworski, 2014), speed calming plan for motorized traffic, quality bike parking facilities with secured options, integrated pricing for bike parking, fees for car parking (Martens, 2007; Cervero et al., 2013). Regarding the promotion of bike and ride (B+R) in particular, the leverage effect of bike parking availability, in quantity and quality, on the practice of bicycle-train integration has been highlighted (Martens, 2007; Givoni and Rietveld, 2007, 2008; Krizek and Stonebaker, 2011; Arbis et al., 2016; Sherwin and Parkhurst, 2008). The relative weight of parking availability and feeder routes quality has often been discussed. Cervero et al. (2013) have analyzed several stations of the Bay Area Rapid Transit (BART) in San Francisco, and their study confirms the positive effect of the quality of bicycle parking facilities but suggests that this effect concerns primarily residents living near the station, while improving cycling feeder routes has more impact in increasing the feeder distances and expands the catchment area of cyclists.

Prospective scenarios are used here to forecast at a time when such proactive policies would have implemented favorable feeder conditions for cycles in the station catchment area. A ten-year period is chosen since it is long enough to enable local and

\footnotetext{
${ }^{1}$ Feeder legs concern the journeys between residence and station in the context of this paper.
} 
national policies to emerge and show effects and short enough to assume some continuity in town planning and mobility trends. The aim is to compare contrasting scenarios for access to the station in the near future, in line with the current trend on the one hand, resulting from strong proactive policies to support bicycle use and bicycletrain integration on the other hand.

The two scenarios are to be compared all other parameters remaining constant (mainly station ridership) in order to infer the potential of train users who would change their access mode from car to cycle thanks to these proactive policies. Two ten-year scenarios are identified as well for station ridership, with low or high increase according to population and mobility evolution prospects; in the case of Amboise for instance we use the current trend on the one hand, local planning studies on the other hand (see Section 4.1.4). We end up with four situations after ten years by combining scenarios regarding station ridership with scenarios regarding proactive policies and feeder conditions (Table 1).

Table 1. Prospective situations after ten years

\begin{tabular}{lcc}
\hline & $\begin{array}{c}\text { Low increase in station } \\
\text { ridership }\end{array}$ & $\begin{array}{c}\text { High increase in station } \\
\text { ridership }\end{array}$ \\
\hline $\begin{array}{l}\text { Business as Usual } \text { (BAU) scenario: } \\
\text { bike access conditions in line with } \\
\text { the current trend }\end{array}$ & BAU-L & BAU-H \\
$\begin{array}{l}\text { Proactive Policies }(\mathrm{PP}) \text { scenario: } \\
\text { high quality bike access conditions }\end{array}$ & PP-L & PP-H \\
\hline
\end{tabular}

\subsection{Catchment area and spatial distribution of access modes}

The catchment area of a train station designates the geographic area where residents are likely to access the station to use train services (Hochmair, 2015). A significant amount of research has been done on this topic for planning or transit development policies, with theoretical and empirical approaches; we refer here to empirical measures of number of residents that can potentially use the train on a regular 
basis, based on territory and station accessibility features. We focus on the way different access modes are mobilized by train users within this area. Train attractiveness is the same over the catchment area: train users (both potential and actual) are assumed to be uniformly distributed over this area. This assumption is acceptable in short distance towns such as found in exurban territories.

Station accessibility mostly refers to the distance that train users are willing to travel as the access or egress part of their journey. Often analyzed for urban hub stations, much research about feeder practices concerns walking distances that are considered to be comfortable: the half-mile catchment circle for population in the US for instance (Guerra et al., 2012). Cycling distances to and from the station have been investigated in many contexts, leading to the recent concept of B-TOD as bicyclebased-transit oriented development (Lee et al., 2016). Cycling train users have been shown to have an acceptable access distance of between 2 and $5 \mathrm{~km}$ (Martens, 2004): $1.96 \mathrm{~km}$ as $85^{\text {th }}$ percentile in Korea (Lee et al., 2016), $2.6 \mathrm{~km}$ as an average with a small decay effect of up to $3.5 \mathrm{~km}$ in the Netherlands (Keijer and Reitveld, 2000), $3.2 \mathrm{~km}$ as median in the USA (Hochmair, 2015). Bike catchment areas are known to be larger for trains and rapid transit compared with slower public transportation (Martens, 2004, 2007; Hegger, 2007; Hochmair, 2015).

However, the (as the crow flies) distance-based accessibility indicator is not appropriate for bicycle access (or for walking access) because active modes users are particularly sensitive to detours imposed by infrastructure, which means additional physical effort: barrier effects, search for bicycle facilities, slope avoidance strategy (Winter et al., 2010). The notion of catchment area appears more complex for bike-train integrators than for pedestrians or motorists (Flamm and Rivasplata, 2014). Especially for cyclists, travel time-based accessibility measures can better capture context 
specificities, provided that realistic travel time taking into account detours and slopes is considered (Krygsman et al., 2004).

For this reason we use computed time-indexed modal potential to analyze the catchment area. Time-indexed potentials are defined for each feeder mode as the population able to reach the station within a given time budget. Section 4 devoted to the case study shows how appropriate high resolution datasets and trip planners can be used to compute realistic multimodal travel times to and from the station for various points of the catchment area. Concerning bikes ${ }^{2}$ and pedelecs, the two travel times to and from the station can be quite different if there are slopes along the itinerary. To handle this asymmetry in the travel times we define "feeder time" as the maximum time needed to go to and from the station, given the hypothesis that the modal choice is influenced by the worst case (i.e. the maximum time experienced to go to the station in the morning or to come back at the end of the day). Using this extra definition we define and compute for each investigated mode an x-minute time-indexed modal potential, i.e. a number of residents able to go to and from the station in less than $\mathrm{x}$ minutes in the worst case.

The next section describes how these potentials can be used to model access modal share in different prospective scenarios.

\footnotetext{
${ }^{2}$ From here, for simplicity, the word "bike" will be used to mean only regular non electric bicycle.
} 


\section{Methodology}

\subsection{Mode distribution model within the catchment area}

\subsubsection{Spatial distribution of access modes in the initial situation}

Access modes are distinguished according to whether they are active (walking and cycling) or motorized ${ }^{3}$, and whether a parking space is used or not. Bikes are divided between parked bikes and boarded bikes. A distinction is also drawn between motorist train users who park their car and those who are dropped off at the station. Motorized modes other than cars form a single category called "other motorized", characterized by low use in our context. Although they involve parking use motorized two wheelers are not considered separately since modal share is very low in European exurban territories and has evolved little over previous decades; we assume it will remain as such in the next ten years horizon.

A catchment area (CA) around the station is assumed, outside of which no inhabitant takes the train on a regular basis; the decay effect of distance is taken as being binary. In our modeling the CA corresponds to the modal potential associated to the fastest feeder mode available, which is cars. The maximum acceptable car feeder time sets the isochrone which defines the border of the CA. As already mentioned, train users within the catchment area are assumed to be uniformly distributed over the population (short distances cities). Inhabitants thus share the same probability of being train users wherever they live inside the CA, but their access mode depends on how far away they live from the station.

\footnotetext{
${ }^{3}$ Pedelecs are considered as belonging to the active category since their motor supports pedaling up to $25 \mathrm{~km} / \mathrm{h}$ only and stops assistance when pedaling stops.
} 
We assume a two-nested zone access mode share model: a central zone close to the station where active modes are possible and actually used, and a surrounding external zone devoted to motorized access (Fig. 1a); access modal share is assumed to be constant in each zone. When access mode share and volumes are known for the initial situation, the central zone can be derived from the spatial distribution of the population: it corresponds to the smallest modal potential that covers the whole set of active train users, pedestrians and cyclists. In the initial situation, the fastest and therefore furthest used active mode is bikes since hardly any pedelec is used as access mode. Thus the bike time-indexed modal potentials are used to derive $\mathrm{T}$, the minimum bike feeder time enabling the potential to cover the volumes of active train users. The Tminute time-indexed bike potential defines the central zone. The value of $\mathrm{T}$ gives the maximum time taken by cyclists in the area to access the station; it determines the line of the boundary between the central zone and the external zone in the catchment area (see Figure 1a).

Figure 1. Spatial distribution of access modes in the initial situation (a), the Business as Usual scenario (b) and the Proactive Policies scenario (c) 


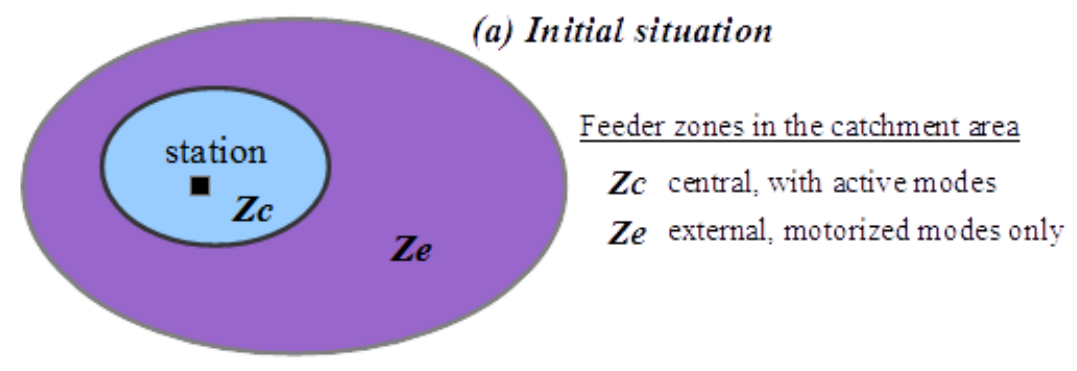

(b) Business as Usual scenario

(c) Proactive Policies scenario

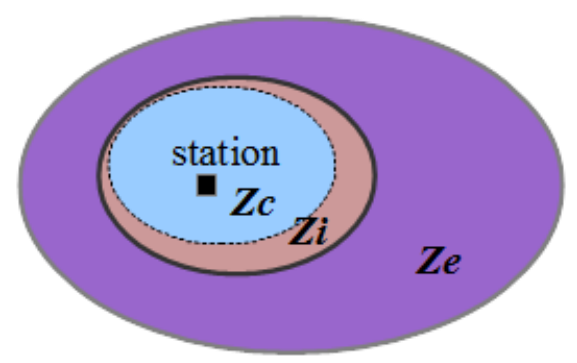

Additional feeder zones

$Z i$ internal, with active modes (pedelecs only)

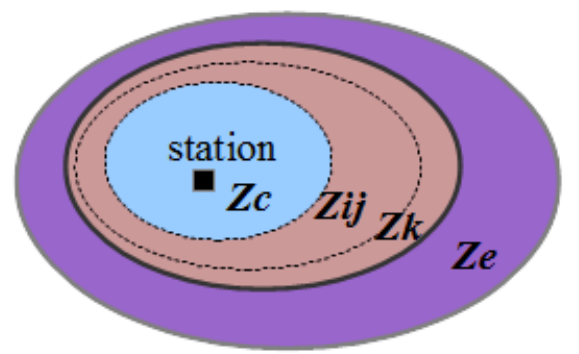

Additional feeder zones

$Z i j$ internal, with active modes (bikes and pedelecs only)

$Z k$ internal, with active modes (pedelecs only)

\subsubsection{Evolution of access mode under prospective scenarios}

The model of the two-nested zones for access choice distribution enables us to embed in the territory the different hypotheses for the evolution of cycling access. In the forecasted horizon of ten years the catchment area remains unchanged, without major changes in road networks or in car feeder time. Housing location is assumed to remain the same over the period; the growth in population and in the proportion of train users follows the initial spatial distribution.

Pedelec development impact: the Business as Usual scenario. In the Business as Usual (BAU) scenario no particular public policies are adopted to favor cycling access to the station area; cycling access conditions remain basically unchanged and so does the maximum cycling access time $\mathrm{T}$ accepted and actually occurring in the area. However, some changes in bicycle mobility are assumed to occur on a larger scale. National 
policies encouraging sustainable mobility favor or enforce the creation of some secured parking spaces for cycles at stations; this is currently the case in France through the “Action plan for active mobilities" (as part of French decree 2015-808, www.legifrance.gouv.fr). In addition, a significant increase in pedelec ownership and usage is assumed to continue during the ten-year period (Dozza et al., 2016; www.bikeeu.com). These trends create conditions to transform pedelecs into a significant access mode to stations with significant share and volumes. Pedelecs being faster than bikes, accessing the station in less than $\mathrm{T}$ minutes becomes possible from further out than the central zone; the T-minute pedelec modal potential draws a larger boarder. A new zone called intermediate zone $(\mathrm{Zi})$ appears in the catchment area between the central and external zones, where access market share of pedelecs can overtake that of motorized modes (Fig. 1b). Train users located in $\mathrm{Zi}$ represent the stock of modal shift that can be induced by pedelec development starting from scratch. The external zone devoted to motorized mode is therefore further reduced.

High quality bike access conditions: Proactive Policies scenario. The Proactive Policies (PP) scenario is based on the same assumptions concerning the growth of pedelec use, but further assumes that ambitious, continuous and coordinated local policies have created good cycling access conditions in terms of:

- Bicycle parking devices at the station: extensive, good-quality and both secured and free-access;

- Restricted car parking and calming motorized traffic conditions in the vicinity of the station;

- Good cyclability of access routes to the station (infrastructure, security, road signs, etc.); 
- Promotion and communication initiatives to encourage bicycle use and bicycletrain integration.

Such cycling access conditions induce modal shift from car to cycle, the potential of which can be outlined using our model. Our central hypothesis is that these attractive cycling conditions make bicycle-train integration more attractive and acceptable for longer (in time) access stages to the station. The maximum cycling access time $\mathrm{T}$ becomes $\mathrm{U}>\mathrm{T}$; it defines in the catchment area two broader bike and pedelec access time isochrones. Two additional internal zones $\mathrm{Zj}$ and $\mathrm{Zk}$ appear between $\mathrm{Zi}$ and the external zone; train users located in these zones represent an additional stock for modal shift from car to cycle and pedelec (see Figure 1c where $\mathrm{Zij}$ stands for the union of $\mathrm{Zi}$ and $\mathrm{Zj}$ ). The external zone devoted to motorized mode is now greatly reduced and pushed out to the extreme ring of the catchment area. Different approaches can be chosen to give a value to time $\mathrm{U}$. We propose to use the duration of the train stage, which gives a good upper bound of the access stage, at least when the total journey duration is less than about an hour (Krygsman et al., 2004). Some transportation executive authorities recommend maximum values in cycle design guidelines, like 20 minutes for Transport Scotland (2011). 


\subsection{Modal shift intensity (Proactive Policies scenario)}

In this section we focus on the Proactive Policies scenario and describe the general assumptions that can be done about the modal shift after ten years of proactive policies favoring cycling feeder conditions.

\subsubsection{Assumptions for car to cycle shifts}

In line with our access mode spatial model, modal shifts are assumed to be constant in each zone. For simplification purposes we only consider modal shift between car and cycle modes. Modal share for other motorized is assumed to remain unchanged: by favoring cycling access it is possible to keep local public transportation services at their present (low) level and to contain powered-two-wheeler development. Modal share for walking is also assumed to be constant, possible shifts between walking and cycling in the central zone canceling one another out. Modal shifts are thus car to bike and car to pedelec, and bike to pedelec since pedelec market share overtakes that of regular bikes as well (Table $2 \mathrm{~b}$ ).

Table 2. Prospective scenarios: modal shifts in accessing the station

(a) Business as Usual scenario

\begin{tabular}{ccc}
\hline Zc & $\mathrm{Zi}$ & $\mathrm{Ze}$ \\
\hline $\mathrm{Car} \rightarrow$ Pedelec & Car $\rightarrow$ Pedelec & - \\
Bike $\rightarrow$ Pedelec & & \\
\hline
\end{tabular}

(b) Proactive Policies scenario

\begin{tabular}{cccc}
\hline Zc & Zij & Zk & Ze \\
\hline Car $\rightarrow$ Bike & Car $\rightarrow$ Bike & Car $\rightarrow$ Pedelec & - \\
Car $\rightarrow$ Pedelec & Car $\rightarrow$ Pedelec & & \\
Bike $\rightarrow$ Pedelec & & & \\
\hline Zij stands for the union of Zi and $\mathrm{Zj}$ & &
\end{tabular}

The impact of improved conditions for cycling access on the actual practice mainly parking facilities and route cyclability - is well documented but its importance is highly context-dependent. No model can anticipate the quantified impact of package of 
measures in a particular territory. Another component of ambitious proactive policies is used that is more directly structuring, namely the restriction, in number and access conditions, of car parking at the station, as a major lever to limit and reduce traffic around the station. Once the maximum number of parking spaces that local stakeholders wish to assign to car parking has been defined, this capacity, combined with an increase in the number of train users on the horizon of ten years, leads to a (minimum) rate of modal shift for car-parking train users. The capacity constraint adopted in the PP scenario is to maintain the current number of parking spaces after ten years, regardless of the changes in demand. We take carpooling into account when converting parked car to $\mathrm{P}+\mathrm{R}$ travelers using an occupancy factor, and do not anticipate a factor increase in the future in this context of short distance access trips.

Different modes are more suited to different ranges of distances, it is thus necessary to differentiate between different modal shifts depending on the zones of the catchment area: when moving away from the station the car to cycle shift rate decreases and is more in favor of pedelecs. Regarding car users moving to cycles, the substitution rate is higher for parked car users $(\mathrm{P}+\mathrm{R})$ than for dropped-off car users, since drop-off may be constrained by the driver's own trip and is not sensitive to parking fees; we adopt a factor 2 between these two rates.

\subsubsection{Assumptions for parked versus boarded bikes}

The new cyclists have to be allocated between parking bike and boarding bike categories. The sizing of the cycle parking is not structuring or limiting as car parking is, since the space that is necessary to park is at least 15 times lower for bikes (Héran, 2003; Celis and Bølling-Ladegaar, 2008), and even less with two-tier solutions available for cycle parking. Pedelecs are generally heavier than regular bikes because of the weight of the battery and electric motor: they are all assumed to be parked. For regular 
bikes the predictable evolution in ten years of the boarding rate depends on two factors: the spread of folding bikes for cyclist train users and the constraints set by the train operator on the boarding of non-folding bikes. The favorable bike access conditions set after ten years will cause a major increase in the rate of folding bicycles among cyclist train users, this equipment rate being higher than for the general population. Within the framework of proactive policies in favor of bike access, we assume that the boarding of non-folding bicycles remains possible while being limited; boarding will remain at its current level relative to the total number of train users. 


\section{Case study}

The time horizon is set at 2025 in the Amboise case study, roughly ten years after field observation and reconstitution of the commuting market.

\subsection{Catchment area and access mode share model in Amboise area}

\subsubsection{Time-indexed modal potentials in Val d'Amboise}

To define bicycle potential based on realistic travel time in Amboise area several tools and data sources are used. The main data source concerns the spatial localization of population around the station. The French Institute for Statistics and Economic Studies (INSEE) delivers high resolution population data (www.insee.fr) in the form of population counts over a high resolution grid built from 200m x 200m cells. This grid dataset follows the INSPIRE specification for interoperability of spatial datasets and is available for all of France. Figure 2 shows the data for our case study Val d'Amboise. Let us notice that for other countries such high resolution data are not always available but should become more easily accessible in the near future. Such a dataset is perfectly suited for the study of feeder potential, thanks to its high spatial resolution; the potential of population able to reach the station within a certain time budget can be precisely estimated provided that travel time can be computed between each cell of the grid and the station.

Figure 2. Population per 200m x 200m cell in Val d'Amboise, with the 200-meter grid from INSEE data 


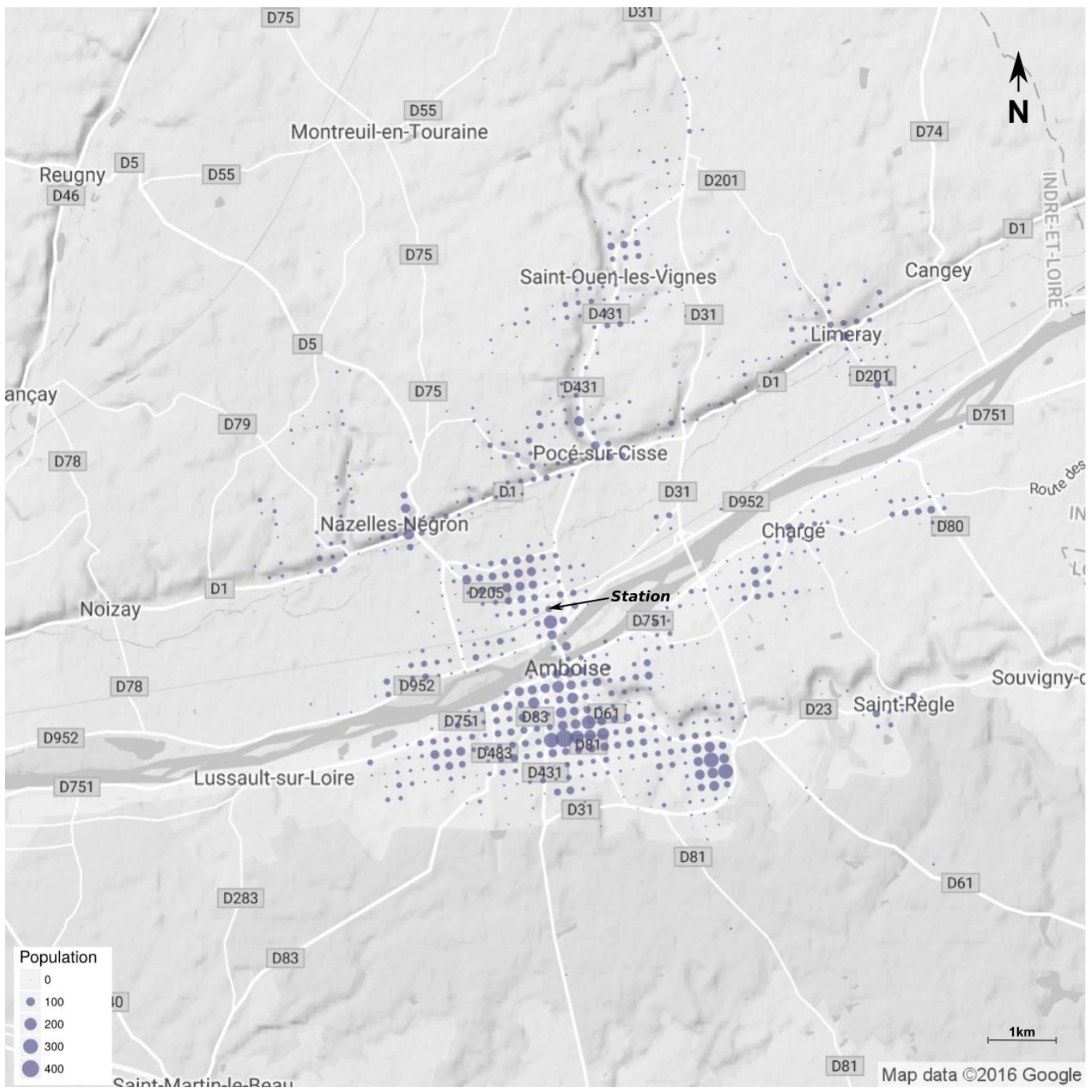

To compute these travel times for each of the cells, a multimodal trip planner software called Open Trip Planner was used, together with two additional datasets. This software has already been used for transit system analysis (Narboneta and Teknomo, 2014; McGurrin and Greczner, 2010); it implements a trip planner for cycling which can be parameterized. It is able to handle network data with cycling infrastructure information and can also take into account the land form of the territory. The trip planner is provided with road network information coming from Open Street Map (available online at download.geofabrik.de) and elevation data from a $25 \mathrm{~m}$ digital 
elevation model provided by the French National Geographic Institute (available online at professionnels.ign.fr/bdalti).

Using this software and dataset the travel times to the station are computed for each cell of the population grid using two different sets of parameters: one for (non electric) bikes and one for pedelecs. For the pedelecs, the slope of the itineraries was not taken into account whereas it was used for the bikes; this choice was made in order to model the electrical assistance provided by the pedelecs. The mean speed on flat roads was set to $14 \mathrm{~km} / \mathrm{h}$ for bikes and $17 \mathrm{~km} / \mathrm{h}$ for pedelecs. Using these settings, it was possible to estimate a precise figure of the potential population able to reach the station within a given time budget by bike or by pedelec; an example is depicted in Figure 3.

Figure 3: The 13-minute time-indexed modal potentials for bikes and pedelecs in the Amboise station catchment area

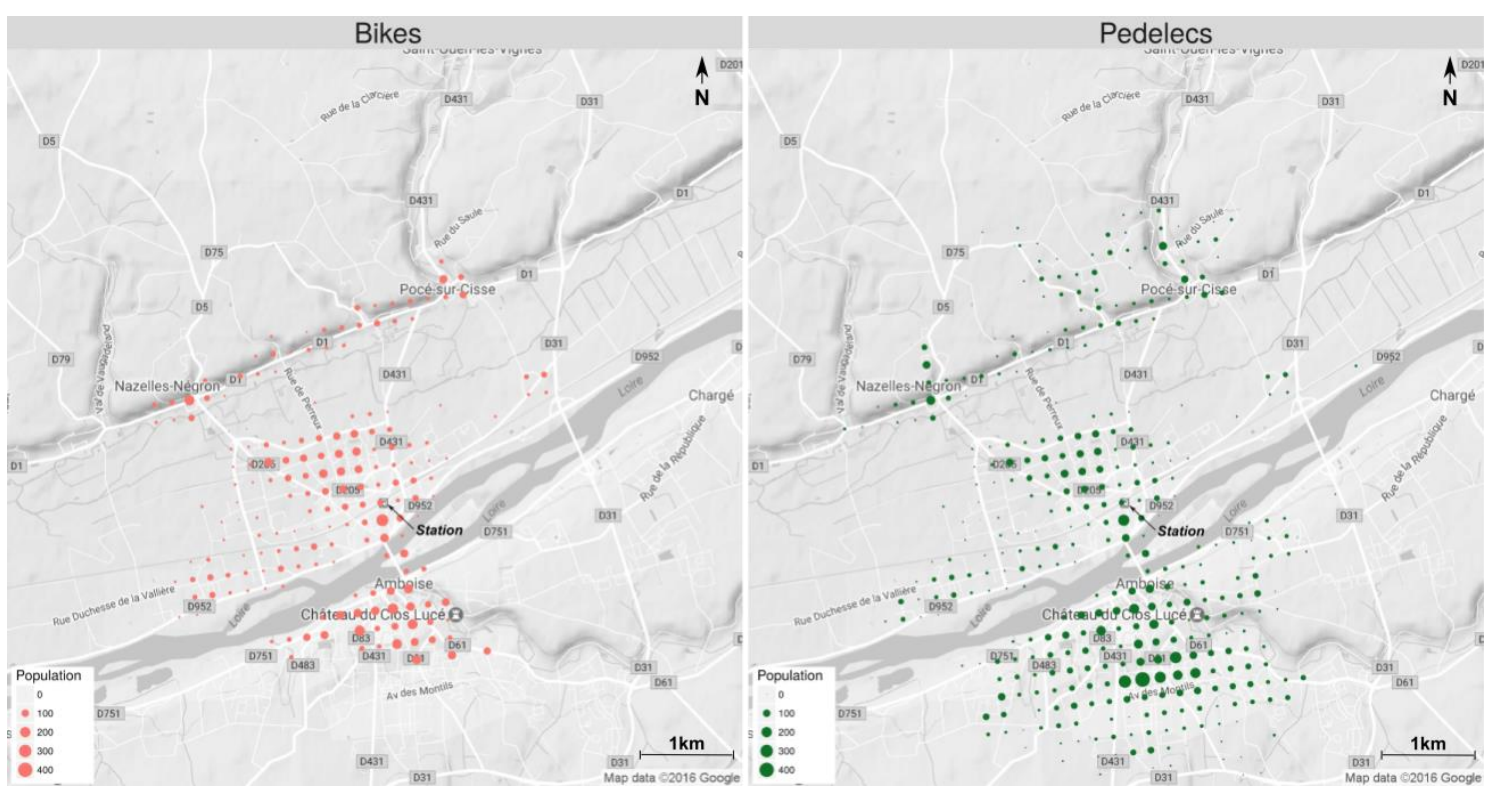

To get a similar result for cars, the same network from Open Street Map is used with OSRM (project-osrm.org), a routing engine dedicated to this mode of transportation. This software allows the computation of time-indexed modal potential of the same type as for bikes and pedelecs. 


\subsubsection{Spatial distribution of access modes: initial situation and prospective scenarios}

In Amboise the catchment area is defined by the 10-minute car modal potential; this 10-minute threshold keeps the whole journey toward Tours competitive in time compared to car from door to door, and designs a potential covering most of Amboise area population. It partly covers 7 municipalities including Amboise and includes 20,836 inhabitants (2014 data). Two municipalities from the west side of the initial car modal potential have been removed since their inhabitants would access another train station closer to Tours. Given the total commuting market, the train market share and the modal share of access modes as reconstituted for the 2014 initial situation (Papon et al., 2017), there are 651 access train users (TU) with the mode distribution given in Table 3.

Table 3. Amboise access modal share and volumes in present situation (651 train users)

\begin{tabular}{|c|c|c|c|c|c|}
\hline \multicolumn{3}{|c|}{ Active modes } & \multicolumn{3}{|c|}{ Motorized modes } \\
\hline Walking & & & & & $\begin{array}{c}\text { Other } \\
\text { motorized }\end{array}$ \\
\hline $22.8 \% / 148$ & & & 66.3 & 432 & $4.0 \% / 26$ \\
\hline & Parked & Boarded & Parked & Drc & \\
\hline & $3.5 \% / 23$ & $3.4 \% / 22$ & $447 \% / 291$ & $216^{0}$ & \\
\hline
\end{tabular}

Source: survey for the research project

Nearly $30 \%$ of travelers accessing Amboise station use active modes, one quarter of whom are cyclists. No pedelec is used as access mode, regular non-powered bikes are the fastest and furthest used active access mode. A little more than $30 \%$ of the catchment area population - thus $30 \%$ of the train users with our hypothesis - is located within the 13 -minute bike potential; respectively $29 \%$ within the 12 -minute bike potential and $41 \%$ within the 14 -minute bike potential. Thus, the maximum accepted time for accessing Amboise station by walking or cycling is roughly 13 minutes. The value of $\mathrm{T}$ is thus found to be 13 minutes, since the 13 -minutes time-indexed bike potential matches the number of active train users while the 12-minutes potential is too 
small (see Section 3.1.1). The two nested zones model for Amboise initial situation gives $34 \%$ of the catchment area population living in the central area where active modes can be mobilized to access the station, and $66 \%$ living in the external zone where only motorized access modes are found.

Under the BAU scenario, the $\mathrm{Zi}$ additional zone defined by the 13-minute pedelec access time isochrone covers $16 \%$ of the population and thus $16 \%$ of the access TU; the external zone is thus reduced from $66 \%$ to $50 \%$ of the catchment area. With PP scenario hypotheses, an additional $20 \%(\mathrm{Zj})$ and $11 \%(\mathrm{Zk})$ of access train users fall into the potential of modal shift from motorized to cycling access zone, with the increase to 20-minute modal potentials for bike ( $\mathrm{Zj})$ and pedelec ( $\mathrm{Zk})$ access $(20$ minutes corresponding to the duration of the train stage between Amboise and Tours). The potential of inhabitants that can access the station using active modes rises from $34 \%$ in the initial situation to $81 \%$ in 2025 according to the PP scenario (Table 4). Of course, not all $81 \%$ change; the next section describes how the assumptions for estimating the magnitude of the mode split in the PP scenario apply in the Amboise case study.

Table 4. Amboise station catchment area: population distribution between feeder zones

\begin{tabular}{lllll}
\hline Initial situation & Zc: $34 \%$ & \multicolumn{3}{c}{ Ze: $66 \%$} \\
\hline Business As Usual scenario & Zc: $34 \%$ & Zi: $16 \%$ & \multicolumn{2}{c}{ Ze: $50 \%$} \\
Proactive Policies scenario & Zc: $34 \%$ & Zij: $36 \%$ & Zk: $11 \%$ & Ze: $19 \%$ \\
\hline
\end{tabular}

In gray: population that can access the station using active modes

$\mathrm{Zij}$ stands for the union of $\mathrm{Zi}$ and $\mathrm{Zj}$

\subsubsection{Specific assumptions in the Amboise case study}

Modal shift intensity (Proactive Policies scenario). The shift rates between car and cycle related to the PP scenario in Amboise are given in Table 5b. The figures are consistent with the general assumptions described previously, including the car to cycle shift rate decay from the center $(100 \%)$ to the boundary (0\%). In between, values for $\mathrm{Zij}$ 
and Zk have been selected to satisfy the capacity constraint on car parking. We will discuss sensitivity analysis later in the next section.

Table 5. Prospective scenarios: modal shift intensity per zone

(a) Business as Usual scenario

\begin{tabular}{cccc}
\hline & Zc & Zi & Ze \\
\hline Parked car $\rightarrow$ Pedelec & $20 \%$ & $20 \%$ & $0 \%$ \\
\hline Bike $\rightarrow$ Pedelec & $10 \%$ & - & - \\
\hline
\end{tabular}

(b) Proactive Policies scenario

\begin{tabular}{ccccc}
\hline & $\mathrm{Zc}$ & $\mathrm{Zij}$ & $\mathrm{Zk}$ & $\mathrm{Ze}$ \\
\hline Parked car $\rightarrow$ \{Bike, Pedelec $\}$ & $100 \%$ & $80 \%$ & $60 \%$ & $0 \%$ \\
$\%$ Pedelec in $\{$ Bike, Pedelec $\}$ & $10 \%$ & $25 \%(\mathrm{Zi})$ & $100 \%$ & - \\
\hline Bike $\rightarrow$ Pedelec & $10 \%$ & $50 \%(\mathrm{Zj}=\mathrm{Zij}-\mathrm{Zi})$ & & -
\end{tabular}

Spread of folding bike for cyclist train users (Proactive Policies scenario). The rate of folding bicycles among cyclist train users is set at $35 \%$ in 2025 compared to $10 \%$ in the initial situation.

\subsubsection{Scenarios regarding station ridership}

The change in station ridership over ten years depends on population and mobility evolution. Mobility is assumed to follow population trend. The first scenario regarding station ridership (low increase) extends the trend between the 2006 and 2011 population censuses; this leads to a 5\% increase between 2014 and 2025. The second scenario (high increase) relies on the Amboise area planning document SCoT and its forecast for population development, which leads to an $11 \%$ increase. Train market share, currently $10.4 \%$ for residents, is assumed to be $11.3 \%$ in 2025 in the trend forecast based on national data for train mobility; the second scenario is based on the assumption of a doubling of train market share, which gives $20.8 \%$. The combination of the low (respectively high) hypothesis for mobility and train market share leads to 1,492 rail trips (respectively 2,886 rail trips) for residents in 2025 , compared to 1,302 today. The 
scenarios regarding station ridership are thus built with factor 1.15 for train users compared to the present for the low increase hypothesis, and with factor 2.22 for the high increase.

\subsection{Resulting situation over ten year}

\subsubsection{Proactive Policies and high increase in station ridership: PP-H situation}

Without change in the current modal share, the 1,443 estimated train users for 2025 would be made up of 958 motorists with 645 P+R users, and 100 cyclists. By applying the modal shift rate hypotheses for Proactive Policies scenario for each zone then summing over the catchment area, we get the following modal share: 510 car users including $284 \mathrm{P}+\mathrm{R}, 548$ cyclists, 328 pedestrians, and 57 other motorized modes. Most $\mathrm{TU}(80.6 \%)$ shifting from car to cycle would be $\mathrm{P}+\mathrm{R}$ users; this result comes from the initial proportion of $\mathrm{P}+\mathrm{R}$ compared to drop-off, and from its dual propensity to switch modes. It appears that shifts from $\mathrm{P}+\mathrm{R}$ to cycle are $72 \%$ in $\mathrm{Zij}, 17 \%$ in $\mathrm{Zk}$ and $11 \%$ in Zc.

Figure 4. Proactive Policies scenario, modal share per zone

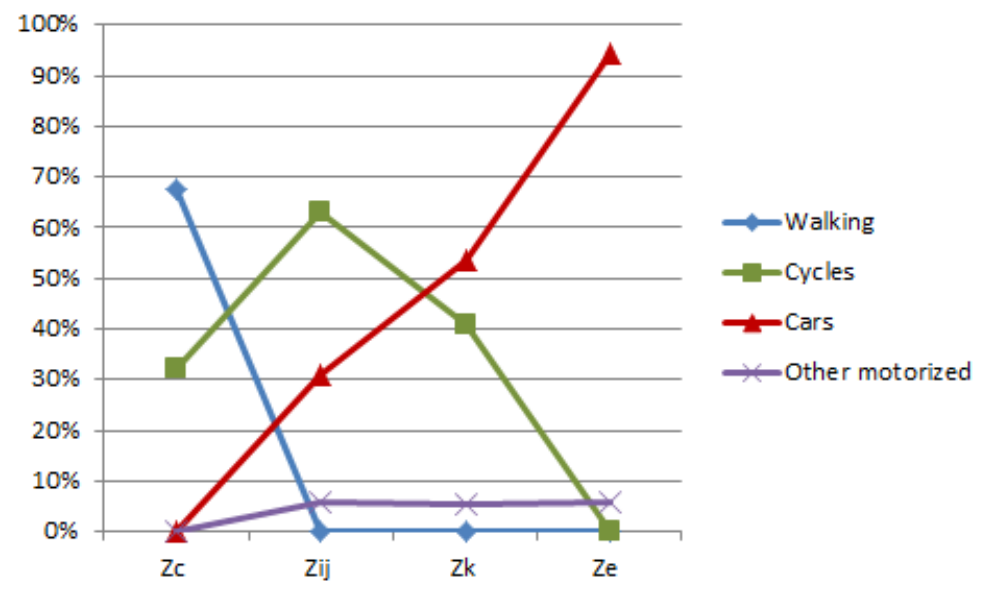

Access with active mode covers all but the external zone (Fig. 4; Fig. 5): the central zone around the station is where one walks, $\mathrm{Zij}$ where one cycles, and $\mathrm{Zk}$ where 
one rides a pedelec. Car use is nonexistent in the central zone in accordance with our assumptions, is minimal in $\mathrm{Zij}$, equivalent to pedelec in $\mathrm{Zk}$ and almost exclusive in $\mathrm{Ze}$. Over the whole catchment area cycle and car modal shares are almost the same: $37.9 \%$ for cycles and $35.4 \%$ for cars. Access by regular bike is the same as walking, about $23 \%$ (Table 6b).

Once cyclist counts are known, hypotheses on boarding conditions are applied to estimate the cycling parking spaces needed. By construction, car parking remains substantially unchanged from the initial situation, which is about 260 spaces, taking into account carpooling. Among the 327 bike TU, 156 board their bike (114 folding and 42 non-folding bikes). A total of 392 TU park their cycle: 221 pedelecs and 171 regular bikes. Applying the recommendation of secure parking facilities for nearly half of the regular bikes the number of parking spaces gradually required for the ten-year period will be 300 secured and 100 free spaces. Pedelecs represent $40 \%$ of cycles. $72 \%$ of cycles are parked at the station. Among the boarded bikes almost three out of four are folding bikes (Table 6b).

Figure 5. Spatial distribution of access modes in Amboise station catchment in the Proactive Policies scenario 


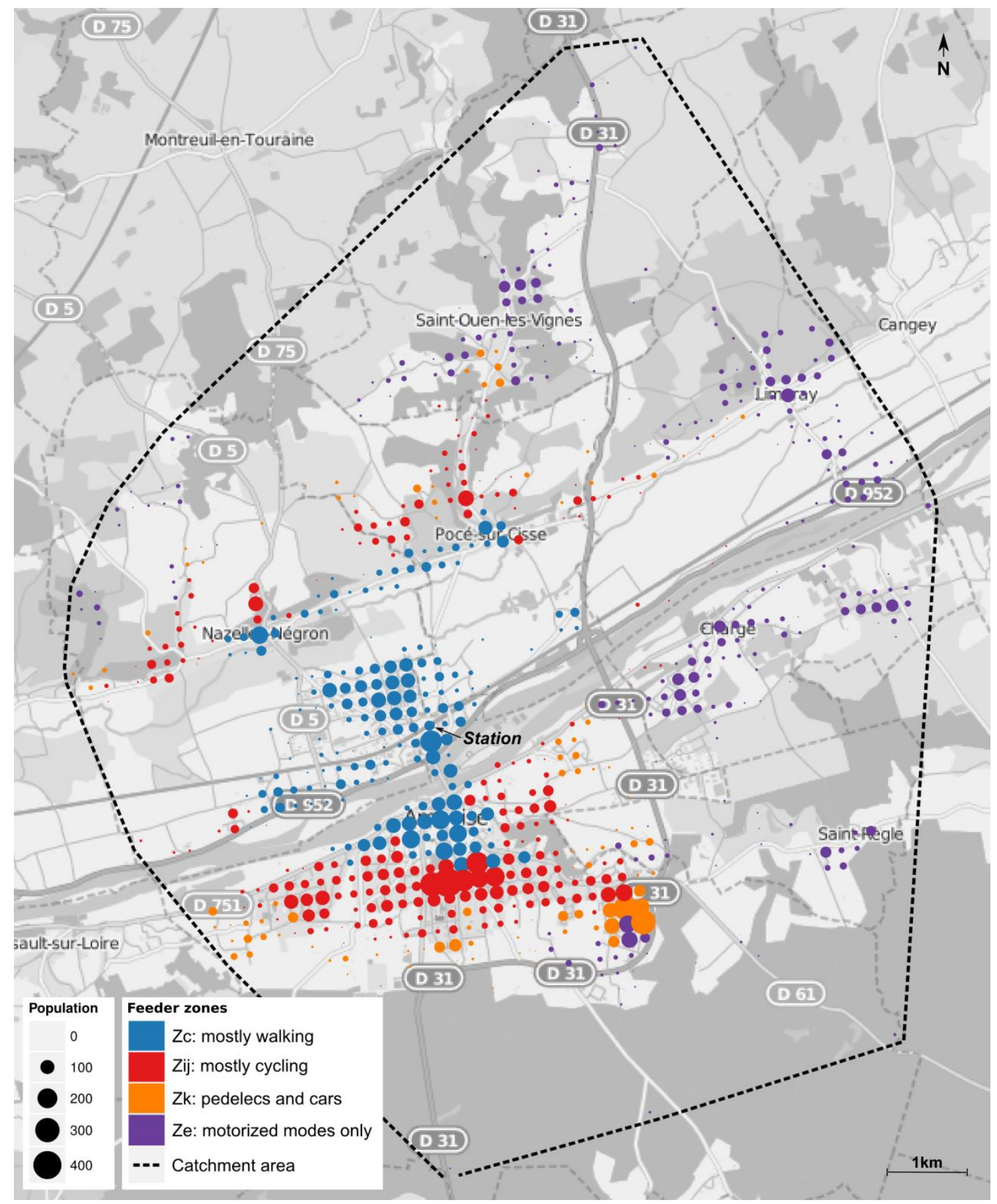


Table 6. Prospective scenarios in the Amboise case study: modal share and volumes (high increase in station ridership hypothesis)

(a) Business as Usual scenario

\begin{tabular}{|c|c|c|c|c|c|c|}
\hline Walking & \multicolumn{3}{|c|}{ Cycles } & \multicolumn{2}{|c|}{ Cars } & $\begin{array}{c}\text { Other } \\
\text { motorized }\end{array}$ \\
\hline $22.7 \% / 328$ & \multicolumn{3}{|c|}{$10.1 \% / 146$} & \multicolumn{2}{|c|}{$63.2 \% / 912$} & $4.0 \% / 57$ \\
\hline & \multicolumn{2}{|c|}{ Bikes } & Pedelecs & & & \\
\hline & \multicolumn{2}{|c|}{$6.2 \%(90)$} & $15.3 \%(56)$ & & & \\
\hline & \multirow{2}{*}{$\begin{array}{c}\text { Parked } \\
\text { Bikes } \\
2.7 \% \\
(39)\end{array}$} & $\begin{array}{c}\text { Boarded } \\
\text { Bikes }\end{array}$ & \multirow{2}{*}{ (all parked) } & Parked & Drop-off & \\
\hline & & $\begin{array}{c}3.5 \% \\
(51)\end{array}$ & & $\begin{array}{c}42.1 \% \\
(608)\end{array}$ & $\begin{array}{l}21.1 \% \\
(304)\end{array}$ & \\
\hline
\end{tabular}

(b) Proactive Policies scenario

\begin{tabular}{|c|c|c|c|c|c|c|}
\hline Walking & \multicolumn{3}{|c|}{ Cycles } & \multicolumn{2}{|c|}{ Cars } & $\begin{array}{c}\text { Other } \\
\text { motorized }\end{array}$ \\
\hline $22.7 \% / 328$ & \multicolumn{3}{|c|}{$37.9 \% / 548$} & \multicolumn{2}{|c|}{$35.4 \% / 510$} & $4.0 \% / 57$ \\
\hline & \multicolumn{2}{|c|}{ Bikes } & Pedelecs & & & \\
\hline & \multicolumn{2}{|c|}{$22.6 \%(327)$} & $15.3 \%(221)$ & & & \\
\hline & $\begin{array}{c}\text { Parked } \\
\text { Bikes }\end{array}$ & $\begin{array}{c}\text { Boarded } \\
\text { Bikes }\end{array}$ & \multirow{2}{*}{ (all parked) } & Parked & Drop-off & \\
\hline & $\begin{array}{c}11.8 \% \\
(171)\end{array}$ & $\begin{array}{c}10.8 \% \\
(156)\end{array}$ & & $\begin{array}{c}19.7 \% \\
(284)\end{array}$ & $\begin{array}{c}15.7 \% \\
(226)\end{array}$ & \\
\hline
\end{tabular}

Average distances traveled to and from the station by each category of train user are estimated using the average distances per zone weighted by the population concerned. When doing so, a 700-meter radius disc around the station is excluded for calculations of distances and times for cycle and car feeder routes; the heart of the central area concentrates most of the pedestrian train users. Bike TU make feeder trips of $2.6 \mathrm{~km}$ on average, as opposed to $2.0 \mathrm{~km}$ in the present situation, which represents a duration of $11 \mathrm{~min} 30 \mathrm{sec}$ (averages based on both access and egress legs). Pedelec TU make trips of $3.5 \mathrm{~km}$ on average, corresponding to $13 \min 45 \mathrm{sec}$. As for car TU, their average feeder trip increases to $5.3 \mathrm{~km}$ as opposed to $4.4 \mathrm{~km}$ in the present situation, duration being dependent on the traffic situation and congestion.

The PP scenario turns out to be a realistic scenario in terms of distance and time traveled by cyclists, in line with current practice. The car mode is associated with longer trips within the catchment area of the station. 


\subsubsection{Comparison with Business as Usual, situation BAU-H}

The rates for modal shifts to pedelec used for the BAU scenario are given in Table 5a. When applied to the Amboise territory (zone-by-zone derivations then sum over the whole catchment area) these modal shift rates lead to 146 cyclists (90 bikes and 56 pedelecs), and 912 motorists among the 1,443 train users. The modal share remains close to that of the initial situation with a gain of $3.2 \%$ for cycles due to the development of pedelecs as a feeder mode (Table 6a).

Comparing the two situations BAU-H and PP-H for 2025, the number of train users shifting from car to cycle thanks to the proactive policies can be calculated. Again counts are done zone by zone then aggregated on the whole catchment area. The consequence of pro-cycling policies is to transfer 402 motorists to cycling, representing $44 \%$ of the train users (Table 7 ).

Table 7. Transferred train users from car to cycle (high increase in station ridership case)

\begin{tabular}{cccc}
\hline & Bike & Pedelec & Total \\
\hline P+R (BAU) to cycle (PP) & $193(101$ “B+R") & 131 & 324 \\
\hline Drop-off (BAU) to cycle (PP) & $44(23$ "B+R") & 34 & 78 \\
\hline Total new cyclists & 237 & 165 & 402 \\
\hline
\end{tabular}

The economic assessment of these transfers was conducted as part of a multidisciplinary research project; the results, assumptions and sensitivity analyses of this economic assessment are presented in details in Papon et al. (2017). Three categories of costs and benefits are considered: parking facilities (land, investment and operation), feeder travel (expenses and time spent traveling) and indirect impacts (accidents, health impacts of exercise, pollution, greenhouse gas emissions). The balance of the modal shift is positive in all 3 categories. Differences in travel costs, which are associated to private costs (mainly fixed costs for the immobilized vehicle), account for just over half of the balance sheet, the other half corresponding to collective 
benefits across the territory (mainly parking facility cost savings, and active travel health benefits).

Our point here is to investigate the influence on the result of the various assumptions used in developing the PP scenario. The total benefit comes from $90 \%$ of users who would have used $\mathrm{P}+\mathrm{R}$ without proactive policies $(81 \%$ of the shifted train users). The most significant initiative of our PP scenario lies in constraining the size of the car parking facilities to remain at its current level, which leads $53 \%$ of $\mathrm{P}+\mathrm{R}$ users in the BAU scenario to change to cycling. This constraint would not, however, have been satisfied without the use of pedelecs, unless considering that all the $\mathrm{P}+\mathrm{R}$ users shift to bike access in the intermediate area Zij.

Two other parameters are crucial to satisfy the constraint: first, the acceptable cycling access time in bicycle friendly conditions, set to 20 minutes, which determines the size of $\mathrm{Zij}$ and $\mathrm{Zk}$, and second, the modal shift rate for $\mathrm{P}+\mathrm{R}$ users associated with these two zones. These rates are high: $80 \%$ and $60 \%$ respectively. However, the 20minute bike and pedelec modal potentials are defined on the basis of the existing cycling network, and therefore probably overestimated for 2025 since the cycling routes would be improved in the PP scenario. If the overestimation is $25 \%$, the bike and pedelec modal potentials define larger areas for $\mathrm{Zij}$ and $\mathrm{Zk}$, and transfer rates of $\mathrm{P}+\mathrm{R}$ of $60 \%$ and $40 \%$ respectively are sufficient to satisfy the constraint.

Several sensitivity tests have been done to check that the other hypotheses assumed for the PP scenario modify neither the size of the modal shift nor its economic assessment. Different values have been tested for the modal shift to pedelecs with respect to bikes in $\mathrm{Zij}$, and for the rate of folding bikes. Impacts on the global assessment are less than $2 \%$, the additional number of bike parking spaces that might be necessary remaining within the margin of overcapacity previously taken into account. 
Finally, if boarding regular bikes were to be prohibited, the overcapacity of bicycle spaces would contain the additional bikes to be parked and the economic balance would fall by only $0.6 \%$. This shows that the assumptions of the PP scenario do not challenge the bike parking sizing necessary in Amboise station nor the magnitude of the economic balance of the estimated modal shift.

\section{Conclusion}

This paper has proposed a methodology to estimate the modal shift potential from car to bicycle (regular bike or pedelec) for residents accessing a train station in an exurban area. Experimented on a French town, it can be applied to similar exurban territories with good quality train services to neighboring city and unexploited potential for growth for cycle access to the station, i.e. sufficient population living within cycling distance to the station (but not within walking distance). The shift potential is assumed to be met over a ten-year period of proactive policies favoring cycling feeder conditions.

This method computes an ambitious but realistic car to cycle shift potential for accessing the station, based on the actual characteristics of the station area. Putting a figure on this potential can give arguments to convince local authorities to adopt proactive policies favoring bicycle and train integration, and provides concrete elements like sizing the cycle parking infrastructure.

This work highlights the major role of car parking control in order to meet this potential of cycling feeder: the evolution of $\mathrm{P}+\mathrm{R}$ facilities as decided by local authorities over the ten-year period largely determines the potential for cycle access under station ridership hypothesis. A pricing policy that links the price of car parking to the reverse of the distance from the client's residence to the station could help to 
optimize the use of size-constrained car parking by encouraging those motorists living closest to the station to change mode.

This work also illustrates that the use of pedelec as a feeder mode significantly extends the area where residents can reach the station by bicycle. For further changes in modal share, bicycle-friendly proactive policies are needed to create good cycling conditions in terms of bicycle parking, cycling routes and containment of motorized traffic. In these conditions, the travel time of the cycling feeder stage can increase but, in our method, must not be longer than that of the train stage.

The modal shift estimation method is based on high resolution population data and realistic travel time computation for car, bikes and pedelecs at the scale of the catchment area. Similar analyses can be made for egress from the station (travelers alighting and going to work at their destination) provided that high resolution employment data is available. INSEE employment data from the SIRENE register has been used in the Amboise case study and mapped on the 200-meter square grid after geolocation. It appears that the main business areas in Amboise become reachable by bike or pedelec from Amboise station under the proactive scenario hypotheses. This additional cycling potential related to egress further strengthens the benefits of developing bicycle and train integration in such areas.

\section{Acknowledgements}

This research was funded by the French Ministry for Ecology, DRI, Predit program. 


\section{References}

Arbis, D., Hossein Rashidi, T., Dixit, V.D.,Vandebona, U. (2016). Analysis and planning of bicycle parking for public stations. International Journal of Sustainable Transportation, 10, 6, 495-504.

Celis, P., Bølling-Ladegaard E. (2008). Bicycle parking manual. The Danish Cyclists Federation.

Cervero, R., Caldwell, B., Cuellar, J. (2013). Bike-and-Ride: build it and they will come. Journal of Public Transportation, 16, 4, 83-105.

Dozza, M., Bianchi Piccinini, G.F., Julia Werneke, J. (2016).Using naturalistic data to assess e-cyclist behavior. Transportation Research Part F: Traffic Psychology and Behaviour, 41, B, 217-226.

Flamm, B.J., Rivasplata, C.R.(2014).Public transit catchment areas; the curious case of cycle-transit users. Transportation Research Record, 2419, 101-108.

Givoni, M., Rietveld, P., (2007).The access journey to the railway station and its role in passengers' satisfaction with rail travel. Transport Policy, 14, 357-365.

Givoni, M., Rietveld, P. (2008). Bicycle parking facilities at railway stations, is it worth investing in? $48^{\text {th }}$ Congress of European Regional Science Association, August, Liverpool.

Guerra, E., Cervero, R., Tischler, D. (2012). The half-mile circle: does it best represent transit station catchments? Transportation Research Record, 2276, 101-109.

Hegger, R. (2007). Public transport and cycling: living apart or together? Public Transport International, 56 (2), 38-41.

Héran, F. (2003). Les effets pervers des parcs relais. Vélocité, 70, 12-14 (in French).

Hochmair, H.H. (2015). Assessment of bicycle service areas around transit stations. International Journal of Sustainable Transportation, 9 (1), 15-29.

Kager, R., Bertolini, L., TeBrommelstroet, M. (2016). Characterisation of and reflections on the synergy of bicycles and public transport. Transportation Research Part A: Policy and Practices, 85, 208-219.

Keijer, M., Rietveld, P. (2000). How do people get to the railway station? The Dutch experience. Transportation Planning and Technology, 23, 3, 215-235.

Krizek, K., Stonebraker, E. (2011).Assessing options to enhance cycling-transit integration. Transportation Research Record, 2217, 162-167. 
Krygsman, S., Dijst, M., Arentze, T. (2004). Multimodal public transport: an analysis of travel time elements and the interconnectivity ratio, Transport Policy, 11, 3, 265275.

Lee, J., Keechoo Choi L., Leem, Y (2016). Bicycle-based transit-oriented development as an alternative to overcome the criticisms of the conventional transit-oriented development. International Journal of Sustainable Transportation, 10, 10, 975984.

Martens, K. (2004). The bicycle as a feedering mode: Experiences from three European countries. Transportation Research Part D: Transport and Environment, 9, 4, 281-294.

Martens, K. (2007).Promoting bike-and-ride : the Dutch experience.Transportation Research Part A: Policy and Practice, 41, 326-338.

McGurrin, M.F., Greczner, D.J. (2010). Performance Metrics: Calculating Accessibility Using Open Source Software and Open Data. Transportation Research Board 90th Annual Meeting, January, Washington, DC.

Mueller, J., Hunter-Zaworski, K. (2014). Bicycle network connectivity for passenger rail stations, Transportation Research Record, 2448, 21-27.

Narboneta, C., Teknomo, K. (2014). OpenTripPlanner, OpenStreetMap, General Transit Feed Specification: Tools for Disaster Relief and Recovery. Proceedings of the 7th IEEE International Conference Humanoid, Nanotechnology, Information Technology Communication and Control, Environment and Management (HNICEM), 12-16 November, Hotel Centro, Puerto Princesa, Palawan, Philippines.

Papon, F., Beauvais, J.-M., Midenet, S., Côme, E., Polombo, N., Abours, S., BeltonChevallier, L., Soulas, C. (2017). Evaluation of the bicycle as a feeder mode to regional train stations. Transportation Research Procedia, 25, 2717-2736

Sherwin, H., Parkhurst, G. (2008). Exploration of the motivations and existing behavior of bike rail integrators to inform future promotional interventions, $5^{\text {th }}$ cycling and society symposium, University of the West England, Bristol.

Transport Scotland (2011). Cycling by design Revision 1, June 2011. Available at http://www.transportscotland.gov.uk. 
Winters M., Teschke K., Grant M., Setton E., Brauer, M. (2010). Bicycle network connectivity for passenger rail stations. Transportation Research Record, 2190, $1-10$. 